November 24th he had actually lost consciousness for a few seoonds.

The pulse-rate was 34 a minute, increasing on exertion to 37 ; there was a systolic bruit, heard best in the aortic urea. Three days later he consulted me again, saying he had had repeated attacks of giddiness. I lound that his heart intermitted at intervals, had a rate of 32 per minute. and that during the periods of intermission ne manifested symptoms of syncopal giddiness.

On November zoth I saw him in consultation with $\mathrm{Dr}$ Alexander Morison. We found the pulse-rate had dropped

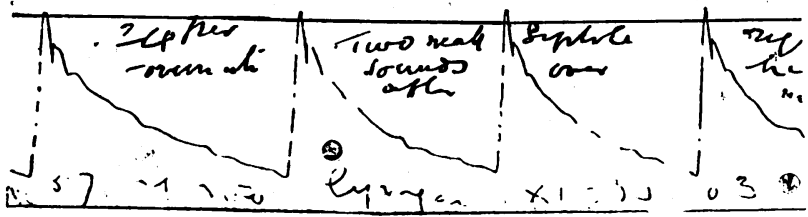

Fig. 1.- November 30 th, 1903 . Left radial recumbent; pulse 24 ; left vent,riuular sysiole, followed by two weak systolic sounds over to 24 there was a well-marked systolic bruit in the aortic area and a full heaving systolic impulse, followed imme. diately by two impulses perceptible to the hand over the position of the right ventricle, and associated with two subsidiary cardiac sounds previous to the recurrence of the succeeding left ventricular systole; and, moreover, that these succeeding sounds were not registered by the sphygmograph, as the appended illustrations will show.

The patient, observed for some days later, evinced practically the same physical signs, although on the whole he felt more comfortable.

On December 6th Dr. Morison again saw the patient with me, and we found that the subsidiary heart sounds follow-

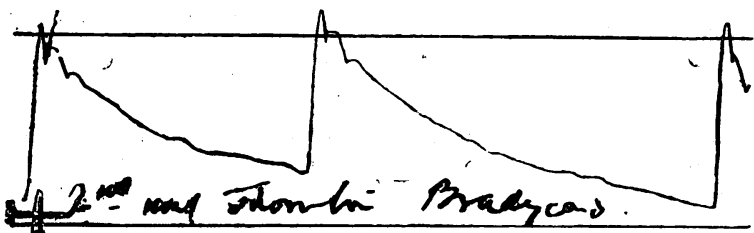

Fig. 2.-December 6th, r903. The same, with slower pulse-rate, showing irregular length of diastolic interval.

ing the left ventricular systole at times numbered three or four, the more forcible of them being associated not only with sound but with impulse; the sounds could be heard both over the heart and over the large veins at the root of the neck; in detecting the sounds the straight stethoscope was found to be distinctly more uselul than the binaural.

The prognosis was necessarily grave, and the patient was enjoined to avoid all stress calculated to affect him injuriously, as experience shows that the termination of such cases is frequently in fatal syncope.

The subsequent history of the case need not be given in detail, the physical signs remained practically the same;

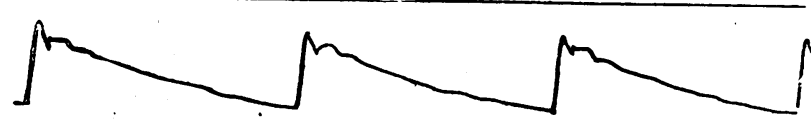

N1498 Rr $P_{32}$

Fig. 3.-December 12th, I903. The same ; pulse 32, and more regular.

at times the patient felt better, and had more regular pulsa tion with fewer sy ncopal attacks; at other times the inter missions were well marked, and the longest duration of such an intermission, timed by myself, was ejght seconds, while the pulse rate varied from 18 to 40 .

It was noticed that, on the whole, when the heart was slowest, which was usually when the patient was in the recumbent position, the subsidiary sounds were most numerous, but they were never registered by the sphygmograph, which only recorded the systole and diastole of the left ventricle.

On April I $7^{\text {th }}$ the patient, who had improved so much in health that I had not seen him for some weeks, went to hi bath-room, and at some period of his ablutions evidently fainted and died suddenly, as his head and shoulders were found under water, and the rest of his body out of the bath. No post-mortem examination was permitted.

Remarks.

The patient was treated with various drug 3 , including strychnine, with and without strophanthus, mercury perchloride, and trinitrin ; strychnine, on the whole, appeared to be most beneficial, while trinitrin was abandoned, as it seemed to have somewhat an injurious effect. The acc lerated influence on the heart's a ction of either stimulants, \& xertion, or trinitrin was very slight. This is in accordance with the usnal experience in these cases.

The chief point of physiological and clinical interest appears to be the undoubted evidence the case affords of an independent action of the two sides of the heart; it will be noticed by reference to the sphygmographs that the descending or diastolic position of the curve shows no evidence of subsidiary pulsations communicated by the heart, and yet the ear and the hand detected secondary impulses which could not hive $f$ illed to have been registered $b v$ the instrument had these originated in the left heart. The conclusion is that the rounds and impulses referred to were produced in the right sidn of the heart during the diastolic pause of the lef ventricle.

\section{THE ALBUMINURIA OF ADOLESCENTS.*}

BY CLEMEN I DUKES, M.D.LOND , F.R.C.P LOND.,

Physiclan to Rugby Bchool and Benior Physician to Rugby Hospital.

DURING the brief time at my disposal I propose to submit for discu-sion a subject at which 1 have worked for a lifetime with ever-widening interest and instruction-the albuminuria of adolescents.

I do not mean the albuminuria which occurs during adolescence, for that would include scarlet fever and diphtheria nephritis. I intend that specific form to which an infinite viriety of names has been assigned, such as "early," "latt nt," "functional," "cyclic," "intermittent," and "posturul." Exh of these terms connotes some feature of the ailment; but the most appropriate name I leave to you to decide. For myst]f, I merely describe the disease as I have found it among boys and girls at school, where it is most commonly to be ob*erved.

The subject is obviously one which intimately concerns every member of the medical profession, whether he be consultant or general practitioner. The interpretation of its significance is still open to debate, and I feel that it ought to be discussed in all its bearings. For withont precise knowledge $u$ reat hardship is apt to be inflicted upon the young who are affected by this form of albuminuria.

In contirmation of the latter observation I mention the following facts:

1. Boys exhibiting the signs of the malady are sometimes sent from school on the ground that they are thus unsuited for the "rough and tumble" of school life. Only a year ago a lad, a patient in whom I was interested, was discharged from school, " because the doctor would not be responsible for him if he were allowed to remain." During his stay at school proteids were removed from his diet; and yet he was + xpected to do his work, and also to provide suitable material for his gruwth. I admit that at one moment his urine would boil like boiled white of egg, though in half an hour not a trace of alhumen might be perceptible. The lad was in good htalth, and the condition of his kidneys indicated no permanent detriment to him-nothing beyond the present loss of alhumen. I have no doubt that he will develop into a vigorous man, free from organic kidney disease.

What a blight upon a young life to be removed from school associations and games and from the comradeship of schoolfellows so essential to growth in manliness, and doomed to the solitariness of a private education and to recreation suitable for an adult instead of a boy!

The only case of this description which I have ever had occasion to remove from school was an only child and fatherless. He was a feeble, delicate, overgrown boy, continuously ailing, and albuminuria was only one of his many weaknesses. I sent him, with a tator, round the world, and he returned a strapping fellow, hearty and strong, and free from albuminuria All his troubles apparently arose from excessive growth, entailing too severe a strain upon a somewhat feeble constitution.

* Read before the South Midland Branch of the British Medical Association at the Annual Meeting held at St, Albans on June and 
2. Boys suffering from this form of albuminuria are also excluded from all public appointments in the navy, army, and Civil Service at home and abroad. About ro per cent. of candidates are refused on this ground at the army examinations and a similar number at those of the Civil Service, although otherwise qualified for appointment. Is it not time that we altered this state of things? It is not to our credit, and it means ruin to the prospects of some of the most promising candidates, without the justification of any valid reason for rejection, as I shall endeavour to show.

3. Life assurance is deferred, or refused to these applicants, except at prohibitive rates; although the instances in which albuminuria is present, in those who seek assurance below 20 years of age, mu st be considerably under I per cent.

By virtue of my office it has fallen to my lot to make a lifelong study of the subject of the albuminuria of adolescents. Daring this time many hundreds of sufferers from the ailment have passed through my hands, under close observation day after day, and many times a day, and in several cases their study has extended over yeara.

If you care to review the history of this malady during the last five and thirty years, you will discover numberless theories, and some of them of the wlldest character, respecting its cause and its importance to the individual.

In papers I have myself written you will be struck by the fact that, while $I$ retain my judgement as to the cause, I have completely changed my conviction with respect to its significance.

Very early in the Seventies I had under my charge many boys poorly from time to time, who, while improving under treatment, did not completely recover their usual health, and the reason quite eluded me. Constantly puzzling over the facts, I definitely diagnosed my first case of this form of albuminuria in 1876 , as belonging to a series which subsequently proved homogeneous in its character and results. After a while I found that, by placing the sufferers from the complaint in bed and giving milk only as food, recovery immediately occurred, quite irrespective of the amount of albumen present, which sometimes was so copious as to alarm me in those early days.

I gradually learnt that, aiter the first fex days, the worst cases even could be kept free of albumen in the vertical position, provided no other food but milk was partaken.

In the process of investigation it was further ascertained that a full meat died could be borne when in the horizontal position without indacing a return of the albumen; while, on the assumption of the vertical position, albumen recurred as abundantly as before if the eame form of diet was continued.

Then I began to examine the urine of every boy who came before me, and discovered the presence of albumen in a large number of unsuspected cases when apparently it entailed no discomfort whatever.

A great number of those who had albuminuria I kept under ebservation day after day; then week after week, and term after term, until the albuminuria bad either dis appeared, or its presence persisting, until the boys had left school, and had passed out of my view as I thought for ever.

From its oontinuance, from its frequent recurrence, and from the pulse tension in a large proportion of instances, $I$ eame to the conclusion that I was witnessing the prologue of a performance whose final scene would be organic disease of the kidneys; so that in the year 1891 I wrote: "I am convinced that a considerable proportion of the cases never recover, but progressively increase."

Yet now, after another long period of investigation, new facts have so forced themselves upon me, that I have completely changed my front, and I hope have arrived nearer to the goal of accuracy.

This reversal of judgement was thus produced. Having held the same appointment for more than thirty-four years some of the sufferers from this form of albuminuris when at school return as men to visit the scenes of their happy schooldays. By various stratagems (imagine their amusement when I acquaint them with my ruse in the pursuit of science), I so inveigle those who presented at school marked and prolonged signs of the malady, that I secure a specimen of urine, and in no instance but one-and in that case this renewed examination occurred shortly after the boy had left school-have I ever found albumen present in the man.

Y ou will naturally say, the experience of one investigator, however assiduous, is not worth much. This I admit. But I beg you to weigh it thoughtfully for what it is worth, as at deast one stepping-stone towards the attainment of truth.

Bear this in mind, ho:ever. If you were to ask my friends what are my manias-as our experimental philosopher Locke says, " Where is the head that has no chimeras in it?" -they would probably reply, looking at the throat, inspecting the skin, and testing the urine. The value of the service which these propensities have rendered me in the position which I hold, I can never gauge; but they have rescued me from many pittalls, my boy patients from much unnecessary suffering, and parents from excessive anxiely and needless expense.

For i have manv times pointed out that a boy who was supposed to be suffering from overwork was merely the victim of albuminuria. Another, who had apparently a weak heart, and all its accompaniments, culminating in fainting, was in reality afflicted with albuminuria, the heart being actually sound, but incommoded, so that neither his work, nor his exercise required restriction. Indeed, so frequent an accompaniment of albuminuria is fainting amongst adolescents, thus clearly revealing the condition of the cardio-vascular system, that, when a boy faints. I examine the urine rather than the heart, and rarely fail to find what I seek.

Adolescents who suffur from attacks resembling those of petit mal are invariably albuminurics when the attacks do not arise from prolonged detigiency of sleep. from known fits of epileps5, or from injuries to the head. Such a patient is under my care at the present moment, who had two attacks at breakfast time on two consecutive mornings during the vacation, and who was ordeced bromides for two years by an eminent physician. $\mathrm{He}$ is, however, a well-marked albuminuric as well as astigmatic, and has now recovered.

I am so familiar with the most common form of this ailment that I can often make an accurate diagnosis even before examining the urine, from the dull, heavg aspect of countenance, from the unstable tension of the pulse, or from the cardiac impulse on the thorax.

There are three types of constitution in which this form of albuminuria chiefly manifests itself :

1. The first, and by far the largest class, exhibit increased arterial tension in consfquence of irritability of the vasomotor nerves; the tension, however, is so unstable that it varies from hour to hour and from day to day, which is pathognomonic of the disease. It is most frequently produced by excess of nitrogenous food, by imperiect action of the gcavengers of the body, and by a hereditary tendency to gout. The albuminuria of adolescents, in all its varieties, is to a considerable extent prevented, and greatly diminished when present, by efficient mastication and by resting a reasonable time after meals-points too little regarded during adolescence. A dose of blue pill and alkalies work wonders, though the proteids may need to be temporarily diminished if the invalid is to continue his school duties.

2. The next most extensive class comprises those who have cold, clammy, swollen, congested extremities, accompanied by a large, feeble, compressible pulse, arising from deficient vasomotor control. The heart participates in the general deficiency of tone, and dilates. Chilblains are frequent, and continue well on into the month of June. The treatment resolves itself in to abundance of food, especially proteids, and the administration of tonics, such as strychnine and arsenic.

3. The remainder are the spare, highly-strung, over-sensitive neurotics. Their relief includes the most equable and least anxious mode of life ohtainable.

The strain of examinations and habitual insufficiency of sleep are answerable for many of these cases; while slowness of progress in school position, implying working under the perpetual dread of superannuation, claims its victims. The pulse in this class is thin, thready, with unstable tension.

The bromides jadiciously administered, with occasional doses of blue pill, affurd alleviation to patients of this type but the only efficien: remedy is the removal of anxiety as far as possible in adaptation to the circumstances of each case, so that the intellectual work may be undisturbed by the intrusion of depressing feeling.

I enter a decided protest against these albuminurics having their education interfered with, their games prohibited, their food supply curtailed, with consequent insufficient nutriment for growth, and their life assurance deferred.

Especially would I urge that they should join in every description of exercise that does not involve competition for prizes, as an excredingly important element in their cure, through ensuring a firmer stability of the cardio-vascular system.

In the year 1899 the governing body of Rugby School arranged that I should make a complete physical examination of boys on their entrance to the school, and, as a result 
of that inspection, I specify the exercise most suitable for each with as little interference as possible with school rules. From the data furnished by these examinations I am engaged in preparing an interesting record, which will occupy me for another three years at least to complete. An analysis of $\mathrm{my}$ register up to the present date in relation to albuminuria shows that at the ages of 13 and 14 -that is, the age for entering on public-school lile-1627 per cent. of boys are affected with albuminuria. I have further unravelled these figures, and find that in January 14.44 per cent., in May 14.26 per cent., and in September 17.84 per cent. of boys are implicated, the largest proportion occurring after the summer and after the long vacation-an experience contrary to what would be anticipated.

I may add, although I have not figures to produce, that this albuminuria increases rather than decreases between the ages mentioned and the close of school life.

One of the greatest difficulties in the knowledge of the history of this malady is the mode of ascertaining the length of time during which the albumen has been in evidence. Has it been unobserved for years, or is it merely a transient condition? At present I am not acquainted with any secure method of judging. The amount of albumen is no criterion, in consequence of its exceptional variation - the oldest and the newest cases showing each a mere trace, or the largest possible quantity.

At the commencement of this term, I examined a " new boy," in rotation, who looked the picture of health, but on boiling his urine it assumed the colour of milk, so loaded was 1t with albumen. I had never seen him before, and no mention was made of this ailment in the personal medical history which was furnished. Next morning there was the merest trace, and the following morning none. He may have had it, on and off, for years, or I may have seen its first onset. Although I bave worked at these cases for more than a generation, I am no nearer the solution of this question of its duration.

The albuminuria of adolescents appears to arise from the want of adjustment of the cardio-vascular system to changes of blood pressure, depending upon a certain state of the vasomotor system-which is too readily excited, and as readily inhibited-so that the nerves exert an ineffective control over the blood vessels, and allow serum-albumen to transude through the over-distended capillaries of the kidneys. In fact, we perceive a congestive neurosis, and so long as the hyperaemia is present, which perpetually fluctuates, the liability to the transudation of serum-albumen through the dilated capillaries must continue.

The albumen, therefore, mostly occurs when there is any special stress upon the circulation, as in assuming the vertical position, during active exertion, or after meals. On the other hand, when the strain is diminished, as in the horizontal position, the most copious albuminuria will immediately disappear, and abundant food may be administered: while in the vertical position the taking of milk aione may be able to prevent a recurrence of the albumen.

When the circulation is thus unstable from defective innervation of the blood vessels-a condition exceedingly common, as I have shown, during the years of growth-the albuminuria may repeatedly recur, even after apparent recovery. The most trivial causes throw the system out of gear in this respect-such as an indiscretion in diet, a constipation, a chill, a cold bath, standing on wet grass, the position of the body, emotion, nervous depression entailing imperfect assimilation of food and the circulation of impurities in the system-with resulting headache, fainting, momentary loss of consciousness, and albuminuria.

The main features, accordingly, of the albuminuria of adolescents are its intermission, the variability in the amoun of albumen present from hour to hour and from day to day, its duration, and the infinite variety of causes and the sligh nature of each-the whole of these conditions depending upon the state of the cardio-vascular system.

The increased cardiac impulse against the chest wall apparently arises, as Sir William Broadbent suggests, from the right ventricle. He remarks "that the apex beat proper, or left ventricle impulse, is, in my experience, weak. This difference has enabled me to diagnose the albuminuria before examining the urine."

The conclusion which I desire to enforce is the fact that when the albuminuria of adolescents is recognized and treated, there is little likelihood of its proving the precursor of onganic disease of the kidneys, even when its duration has been many years.
The general treatment resolves itself into so reasonable a regulation of life as to ensure the highest state of vitality during adolescence :

1. Work, while it may be ample, must not be excessive; and work is always excessive during the years of growth when sleep is insufficient. The hours of both must be detêrmined according to age, as I have so often urged.

2. Exercise should be recreation rather than physical drill, which, by the pleasurable sensations, increases the tone of the whole nervous and vascular system; and anch exercise should be daily.

3. Food should be sufficient for the provision of growth, as well as the renewal of wear and tear, bearing in mind that the adolescent requires more food than the adult, and the girl more than the boy, on account of her greater rapidity of growth.

4. The duties of the scavengers of the body should be so disciplined as to be brought under the habitual control of the will. Natural action should not be replaced by the perpetuah stimulus of aperients, for this vicarious duty obviously confirms the intestines in sluggishness of work, and tends to convert a temporary inactivity into a permanent abandonment of function.

The line of treatment of the individual I have indicated in speaking of the varieties of constitution in which this albuminuria is manifested.

I thank you for the close attention you have given to $\mathrm{my}$ paper; I hope that you will devote an earnest and thoughtiul consideration to.its suggestions in the interests of the coming and future generations.

\section{CASE OF LIGATURE OF THE PROFUNDA FEMORIS ARTERY, COMMON FEMORAL ARTERY, AND COMMON ILIAC ARTERY ON THE SAME SIDE, WITH PERFECT RECOVERY.}

BY HENRY E. CLARK, C.M.G.,

Senior Surgeon, Glasgow Royal Infirmary.

H. B., porier, aged 26, was admitted into Ward 25, Glasgow Royal Infirmary, on April 25th, 1899, suffering from a small punctured wound at the inner side of the left thigh, at the junction of the upper and middle third.

His story was that he and another man were having a fight, when the latter whipped out a penknife, and came at him. In trying to escape from the assault, he fell, and his assailant. fell on the top of him, and the blade of the knife ran into the thigh, right up to the hilt. The wound bled very freely, but. a doetor was soon in attendance, who put on a pad and bandage. When he reached the hospital the bleeding had ceased, and on the following morning, when I saw him at the usual visit hour, the wound was so well plugged with clot that. $I$ thought it unwise to disturb it. All went well till May 12th, when the wound was found to be bleeding freely suppuration having taken place, and the clot having consequently broken down. I thoroughly opened up the wound, and exposed the main trunk of the profunda femoris artery, which had been incompletely divided; this was double ligatured and cut. across. The vein was also found to be injured, and was more difficult to secure effectively than the artery.

Three days afterwards (on May 15th), when the patient was using the bedpan he became suddenly blanched and pulseless, and the dressings became saturated with arterial blood. I was fortunately on the spot at the time, and at once took him to the operating theatre, where I ligatured the common femoral artery just at its emergence from beneath Poupart's ligament. This arrested the bleeding, and he very rapidly recovered from the loss of blood, until five days later (May 2oth), when a still more serious haemorrhage took place. On this occasion also I happened to be in the infirmary, and at once applied an elastic bandage round the pelvis and hip, but as this did not control the bleeding it was decided to ligature the common iliac artery. This was done by Sir Philip Crampton's method, as described by him in the MedicoChirurgical Transactions, vol. xvi, p. 16i, as far back as 1828. The incision commenced at the anterior extremity of the last rib, proceeded downwards directly to the ilinm, then followed the line of the crest, but keeping a little within its inner margin, until it terminated at the anterior superior spine. The abdominal muscles were divided in the full extent of this incision till the peritoneum was reached, when that structure with the contained intestines was lifted 